\title{
The Relationship of Neutrophil Lymphocyte Ratio and Levels of Vitamin D against Disease Activity Systemic Lupus Erythematosus
}

\author{
Ahmad Fauzi Lubis ${ }^{1}$, Zuhrial Zubir ${ }^{2}$, Ananda Wibawanta Ginting ${ }^{2}$ \\ ${ }^{1}$ Department of Internal Medicine, Faculty of Medicine, Sumatera Utara University, Medan \\ ${ }^{2}$ Division of Pulmonary and Alergy Immunology, Department of Internal Medicine, Faculty of Medicine, \\ Sumatera Utara University, Medan \\ Corresponding Author: Zuhrial Zubir
}

\begin{abstract}
Background: Systemic lupus erythematosus (SLE) is an autoimmune disease characterized by the presence of autoantibodies against cell nuclei and immune complexes involving multiple organ systems in the body. The Lupus Foundation estimates about 1.5 million cases of SLE in America and at least 5 million cases of SLE in the world and from year to year, the number of people with lupus also tends to increase. Several laboratory findings are also associated with signs and symptoms of SLE activity including the ratio of neutrophil lymphocytes and vitamin D levels.

Method: This study is an observational analytic study using medical record data from central installation patients at H. Adam Malik Hospital in the period December 2019 to March 2021. The sample is calculated using the large proportion estimation formula. Then the distribution test was carried out with the Shapiro Wilk test. Bivariate analysis was carried out to determine the relationship between neutrophil lymphocyte ratio and vitamin D levels with the MEX SLEDAI score using the ANOVA test if the data was normally distributed.

Results: 75 subjects participated in the study and there were 12 people (16\%) experiencing mild systemic lupus erythematosus, 38 people (51\%) moderate degree, and 25 people $(33 \%)$ severe degree. The neutrophil-lymphocyte ratio was associated with systemic lupus erythematosus disease activity $(\mathrm{p}=0.001)$ and vitamin D levels were associated with systemic lupus erythematosus disease activity.
\end{abstract}

Conclusion: Neutrophil-lymphocyte ratio and vitamin D levels are associated with systemic lupus erythematosus disease activity.

Keywords: neutrophil lymphocyte ratio, vitamin D levels, systemic lupus erythematosus

\section{INTRODUCTION}

The Lupus Foundation estimates about 1.5 million cases of SLE in America and at least 5 million cases of SLE in the world. The prevalence and incidence of SLE in the world vary. Studies in Asia Pacific show incidence data of 0.9-3.1 per 100,000 populations per year with a crude prevalence of 4.3-45.3 per 100,000 populations. In Indonesia, the prevalence of lupus is 0.5 percent or about 1.25 million people. However, only 12 percent of that number is reported. From year to year, the number of people with lupus also tends to increase. In 2014, only 543 hospitals reported treating lupus. That number increased to 621 hospitals in 2015 and 858 hospitals in 2016. $\quad{ }_{1,2}$ Evaluation of SLE disease activity is useful as a guide in the administration of therapy. The index for assessing activity is recommended to use the MEX-SLEDAI or SLEDAI (SLE Disease Activity Index). The most widely used measure of disease activity in international multicenter trials is SLEDAI. MEXSLEDAI is easier to implement in primary health centers. ${ }^{3}$ 
A meta-analysis of fourteen studies with 1,781 SLE patients and 1,330 healthy controls showed that NLR was significantly higher in SLE patients compared to healthy controls. Another study also showed the same evidence, namely the study of Yu et al found that NLR as a diagnostic marker of SLE in SLE patients was higher than controls $(\mathrm{p}<0.05)$ which had a positive correlation with SLEDAI scores $(r=0.237$, $\mathrm{P}=0.01)$ with a cut-off value [2.293; sensitivity (68.9\%) and specificity (82.8\%)]. NLR was significantly increased in SLE patients compared with healthy controls $[\mathrm{EXP}(\mathrm{B})=1.986 ; 95 \% \mathrm{CI}, 1.432-2.753 ; \mathrm{P}$ $=0.001]$ which is positively correlated with SLEDAI-2K. The optimal NLR cut-off value for predicting SLE (2.075; sensitivity (71.14\%) and specificity (69.57\%). NLR was significantly higher in SLE nephritis patients compared to controls $(4.8 \pm 1.4$ vs. $3.8 \pm 2$ ), NLR correlated with SLEDAI with a cut-off value (5.65).,

\section{The Relationship Of Neutrophil \\ Lymphocyte Ratio And Levels Vitamin D Against Disease Activity Systemic Lupus Eritematosus}

Low vitamin D levels are an indicator of an ongoing inflammatory process. Inflammation has the potential to increase vitamin $\mathrm{D}$ metabolism. Previous studies have shown that $71 \%$ of SLE patients have vitamin $\mathrm{D}$ deficiency. Low levels of vitamin D deficiency are very common in SLE patients due to avoidance of sunlight, photoprotection, renal insufficiency and the use of drugs such as glucocorticoids, anticonvulsants, antimalarials and calcineurin inhibitors, which alter vitamin $\mathrm{D}$ metabolism or decrease VDR function. Vitamin D supplementation of 1200 IU, found a significant difference in SLEDAI scores $(\mathrm{p}$ $=0.000)$, found a negative correlation $(\mathrm{r}=$ 0763) between vitamin D levels and disease activity (SLEDAI).Another study found significantly lower $25(\mathrm{OH}) \mathrm{D}$ levels in SLE patients compared to controls $(17.6 \pm 6.9$ $\mathrm{ng} / \mathrm{mL}$ vs. $79.0 \pm 28.7 \mathrm{ng} / \mathrm{mL} ; \mathrm{t}=-11.2$; $\mathrm{p}=0.001$ ). High prevalence of vitamin $\mathrm{D}$ insufficiency $(73.3 \%)$ and deficiency (23.3\%), which had a very significant negative correlation with SLEDAI ( $\mathrm{r}=$ $0.495, \mathrm{P}, 0.001$ ). A systematic review study showed results from three studies showing a positive effect of supplementation on decreasing disease activity and significantly increasing levels of inflammatory markers. Only one study showed no improvement in disease activity after supplementation. ${ }^{6,7}$

\section{MATERIALS AND METHODS}

The design of this study was observational with a retrospective approach to secondary data to determine the relationship between the ratio of neutrophil lymphocytes and vitamin D to the activity of the degree of lupus disease. The research will be carried out at $\mathrm{H}$. Adam Malik Hospital Medan from December 2019 to March 2021 after obtaining ethical clearance from the Health Research Ethics Commission of the Faculty of Medicine, University of North Sumatra (FK USU) and permission from the Health Ethics Commission of Haji Adam Malik Hospital Medan, until the number of samples is met. The research target population is SLE patients, while the affordable patient population is SLE patients over 18 years who come to Haji Adam Malik General Hospital Medan for the period December 2019 - March 2021. Research subjects were taken from the population of SLE patients who met the inclusion and exclusion criteria of the study.

\section{Inclusion Criteria}

1. SLE patients aged 18 years

2. Patients diagnosed with SLE according to the 1997 revised ACR criteria with disease activity were assessed by the MEX SLEDAI score

3. Complete medical record data

\section{Exclusion Criteria}

1. Massive stress (severe trauma, surgery, cardiac shock, burns). 
2. Patients with other autoimmune diseases.

3. Patients with hematological malignancies.

4. Severe liver cirrhosis (Child Pugh C).

5. History of repeated transfusions.

\section{Statistical Methods}

Univariate and bivariate analyzes were performed using statistical software. Univariate analysis to determine the characteristics of SLE patients. Then the distribution test was carried out with the Shapiro Wilk test. Bivariate analysis was conducted to determine the relationship between the ratio of neutrophil lymphocytes and the ratio of platelets to lymphocytes with the MEX SLEDAI score using the Independent T-test if the data was normally distributed, or the Mann Whitney $U$ test if the data were not normally distributed. Then proceed with the correlation test using the Pearson correlation, the data is normally distributed and the Spearman correlation test if the data is not normally distributed. The magnitude of the desired deviation $(\alpha)$ is 0.05 . Statistically significant if $p<0.05$.

\section{RESULT}

\section{Respondent Characteristics}

Based on medical records of patients with systemic lupus erythematosus who were hospitalized at the Inpatient Installation of H. Adam Malik Hospital, Medan from December 2019 to March 2021, 75 research subjects were obtained which aimed to determine the relationship between NLR and Vitamin D to the degree of lupus activity in lupus systemic erythematosus. The demographic and clinical characteristics of the research subjects are presented in Table 4.1. The following is a table that describes the characteristics of the sample in this study.

The number of gender respondents is more female, namely 68 people $(91 \%)$ compared to 7 male respondents $(9 \%)$. The most common clinical manifestations in SLE patients experienced by 73 respondents were arthritis, then malar rash 67 people, immunological disorders 64 people, hematological disorders 59 people, kidney disorders 47 people, photo sensitivity 41 people, discoid rash 40 people, serositis 33 people, neurological disorders 12 people.

Table 1. Characteristics of Research Subjects

\begin{tabular}{|l|l|}
\hline Characteristics & $\mathbf{n}=\mathbf{1 0 0}(\mathbf{\%})$ \\
\hline Age (year) & \\
\hline Mean ( sb) & $31,56(11,39)$ \\
\hline Sex & \\
\hline Male & $7(9,3 \%)$ \\
\hline Female & $68(90,7 \%)$ \\
\hline Arthritis & $73(97,3 \%)$ \\
\hline Malar rash & $67(89,3 \%)$ \\
\hline Serositis & $64(85,3 \%)$ \\
\hline Hematologic disorder & $59(78,7 \%)$ \\
\hline Renal disorde & $47(62,7 \%)$ \\
\hline Discoid rash & $40(53,3 \%)$ \\
\hline Neurologic disorder & $12(16,0 \%)$ \\
\hline
\end{tabular}

\section{Relationship between Neutrophil Lymphocyte Ratio and Vitamin D Levels in SLE}

The mean ratio of neutrophil to lymphocyte in patients with mild SLE is 3.21 , in moderate degrees is 4.44 , and in severe degrees is 9.89. Based on the analysis carried out, a significant relationship was obtained with a $\mathrm{p}$ value $<0.05(\mathrm{p}=0.002)$. The mean level of Vitamin D at the mild degree is 22.40 , at the moderate level is 15.13, and at the severe degree is 12.30. Based on the results of the analysis carried out, a significant relationship was obtained with a $\mathrm{p}$ value $<0.05(\mathrm{p}=0.002)$.

Table. 2 Relationship between Neutrophil Lymphocyte Ratio and Vitamin D Levels in SLE
\begin{tabular}{|l|c|l|l|l|}
\hline \multirow{2}{*}{ Parameter } & The degree of activity of systemic lupus erythematosus & \multirow{2}{*}{ P Value } \\
\cline { 2 - 5 } & mild $(\mathbf{n = 1 2})$ & moderate $(\mathbf{n}=\mathbf{3 8})$ & \multicolumn{1}{|c|}{ severe $(\mathbf{n = 2 5})$} & \\
\hline NLR & $3,21(0,86-6,58)$ & $4,44(1,0-20,56)$ & $9,89(1,25-48,80)$ & 0,002 \\
\hline Vitamin D & $22,40(10,40-40,40)$ & $15,13(4.10-36.30)$ & $12,30(5,60-30,50)$ & 0,002 \\
\hline
\end{tabular}

Correlation of neutrophil lymphocyte ratio and vitamin D levels with MEXSLEDAI scoring
Based on table 2, the results show that the neutrophil lymphocyte ratio has a moderately positive correlation with the 
MEX-SLEDAI scoring with a value of $\mathrm{r}=0.334$ with a $\mathrm{p}$-value of $0.003(<0.05)$.

Based on table 3 , the results show that vitamin D levels have a fairly negative correlation with the MEX-SLEDAI scoring with a value of $r=-0.259$, with a $p$-value of $0.025(<0.05)$.

Table 3. Correlation of neutrophil lymphocyte ratio and vitamin D levels with MEX-SLEDAI scoring

\begin{tabular}{|l|l|l|}
\hline & Statistic & MEX-SLEDAI \\
\hline \multirow{4}{*}{ Neutrofil Limfosit Ratio } & $\mathrm{R}$ & 0,334 \\
\cline { 2 - 3 } & $\mathrm{P}$ & 0,003 \\
\cline { 2 - 3 } & $\mathrm{N}$ & 75 \\
\hline \multirow{3}{*}{ Vitamin D } & $\mathrm{R}$ & $-0,259$ \\
\cline { 2 - 3 } & $\mathrm{P}$ & 0,025 \\
\cline { 2 - 3 } & $\mathrm{N}$ & 75 \\
\hline
\end{tabular}

\section{Correlation of neutrophil lymphocyte ratio with vitamin $D$}

The ratio of neutrophil to lymphocyte has a weak negative correlation with vitamin $\mathrm{D}$ with an $\mathrm{r}$ value of -0.142 with a $p$ value of 0.224 .

Table 4. Correlation of neutrophil lymphocyte ratio with vitamin D

\begin{tabular}{|l|l|l|}
\hline & Statistic & Vitamin D \\
\hline \multirow{3}{*}{ NLR } & R & $-0,142$ \\
\cline { 2 - 3 } & P & 0,224 \\
\cline { 2 - 3 } & $\mathrm{N}$ & 75 \\
\hline
\end{tabular}

\section{DISCUSSION}

In this study, the average ANA value was $94 \mathrm{U}$ and the standard deviation (SB) was 79.57. A positive ANA test is $95-100 \%$, but the ANA test result can be positive in several other diseases that have a clinical picture resembling SLE such as chronic infections (tuberculosis), autoimmune diseases (e.g. Mixed Connective Tissue Disease/MCTD, rheumatoid arthritis, autoimmune thyroiditis), and malignancy. The study by Qu et al. (2018) found that the sensitivity and specificity of ANA in diagnosing SLE were 91.75 and $79.65 \%$, respectively.

Based on laboratory examination, the average neutrophil level was $70.5 \pm$ 13.62 cells $/ \mathrm{mm} 3$, the average lymphocyte level was $19.7 \pm 17.2$ cells $/ \mathrm{mm} 3$, the average vitamin D level was $7.33 \pm 4.13$ cells $/ \mathrm{mm} 3$.In this study, the majority of study subjects with systemic lupus erythematosus were moderate degrees, namely 38 people $(51 \%)$, severe degrees as many as 25 people (33\%), and mild degrees as many as 12 people $(16 \%)$. In this study, the mean ratio of neutrophil to lymphocyte was 6.05 , the average vitamin D level was 15.35 and the average MEX-SLEDAI score was 9.27.

Based on the analysis obtained, there was a statistically significant relationship between the neutrophil lymphocyte ratio (NLR) and the systemic lupus erythematosus grade group with a moderate positive correlation $(\mathrm{r}=0.334)$ and $\mathrm{p}<0.05$ $(\mathrm{p}=0.003)$. This study also found a moderately negative correlation $(\mathrm{r}=-0.259)$ between vitamin $\mathrm{D}$ levels and the systemic lupus erythematosus grade group with $\mathrm{p}<0.05$ ( $\mathrm{p}=0.025)$. In addition, this study found that the ratio of neutrophil to lymphocyte has a sufficient correlation with vitamin D levels with a value of $\mathrm{r}=-0.142$, with a value of $p=0.224$. Several studies have been conducted on the use of the neutrophil-lymphocyte ratio and vitamin D levels in evaluating the activity of systemic lupus erythematosus, namely the study of Oehadian, A et al conducted at Hasan Sadikin Hospital from November 2011 to January 2012 found that the neutrophillymphocyte ratio was significantly higher in SLE compared to normal subjects $(2.52$ (1.01-10.92) vs. 1.65 (0.77-4.59), $\mathrm{p}=0.007$. In the Kambayana study, $G$ et al who conducted in Bali with a total sample of 54 patients with a median age of 28.5 years, most of whom were female $(85.2 \%){ }^{8}$

The results of the analysis of a positive correlation between NLR and disease activity in SLE ( $\mathrm{r}=0.399 \mathrm{p}=0.003$ $\mathrm{n}=54$. Vitamin $\mathrm{D}$ levels were negatively correlated with the MEX-SLEDAI score found in line with Yap,S et al's study which conducted in Australia where from 119 patients who were collected from January 2007 to January 2013, the results of the analysis showed that there was a significant inverse correlation between MEX-SLEDAI scores and vitamin D levels, meaning that there was a significant relationship between low vitamin D and increased MEX-SLEDAI scores. at a later time point (OR 3.3, 95\% CI 
1.5 to $7.7, \mathrm{p}=0.005)$ or had high disease activity (SLEDAI-2k>. Mok et al 2012 from 290 SLE patients found 78 people with low vitamin D levels and 25-hydroxyvitamin D3 levels also inversely correlated with SLE disease activity $\left(\mathrm{Rho}^{1 / 4} \mathrm{4} 0.26 ; \mathrm{p}<0.001\right)$.With the conclusion that the ratio neutrophil lymphocytes were found to be higher in patients with systemic lupus erythematosus, whereas low vitamin D levels were also seen in patients with systemic lupus erythematosus and there was a moderately negative correlation between the ratio of neutrophil lymphocytes and vitamin D levels to SLE activity. ${ }^{9}$ In Guan et al's 2019 research, a systematic study and metaanalysis were carried out with 19 studies. They found that compared with a healthy control group, 25(OH)D levels were significantly reduced in SLE patients with an SLEDAI score of more than 10. Meanwhile, the level of vitamin D where the measurement of circulating $25(\mathrm{OH}) \mathrm{VD}$ is considered the best indicator of measuring vitamin D levels in humans. Storage of vitamin $\mathrm{D}$ is obtained from food intake and light ultraviolet. Low serum Vitamin D levels were significantly associated with SLEDAI scores. The presence of mucocutaneous symptoms, malar rash, and kidney are significantly correlated with vitamin D deficiency. This shows that between $25(\mathrm{OH})$ D serum concentrations and the disease activity category, and when evaluating SLEDAI scores among various $25(\mathrm{OH}) \mathrm{D}$ categories, illustrates that the lower the 25(OH) D, the higher the SLEDAI score and vice versa. ${ }^{10,11}$

\section{CONCLUSION}

Neutrophil-lymphocyte ratio and vitamin D levels are associated with systemic lupus erythematosus disease activity.

\section{ACKNOWLEDGEMENT}

The authors gratefully acknowledge that the present research is supported by the Ministry of Research and Technology and Higher Education Republic of Indonesia.
The support is under the research grant DRPM (Direktorat Riset dan Pengabdian Masyarakat).

\section{Conflict of Interest: None}

\section{Source of Funding: None}

\section{Ethical Approval: Approved}

\section{REFERENCES}

1. Pusdatin RI. Situasi Lupus di Indonesia. Departemen Kesehatan RI. 2017.

2. Justiz Vaillant AA, Goyal A, Bansal P, et al. Systemic Lupus Erythematosus (SLE). StatPearls Publishing; 2020 Jan-. Available from:

https://www.ncbi.nlm.nih.gov/books/NBK5 $35405 /$

3. Thanou A, James JA, Arriens C, et al. Scoring systemic lupus erythematosus (SLE) disease activity with simple, rapid outcome measures. Lupus Science \& Medicine. 2019.;6:e000365. doi: 10.1136/lupus-2019-000365

4. Wang L, Wang C, Jia X, Yang M, Yu J. Relationship between Neutrophil-toLymphocyte Ratio and Systemic Lupus Erythematosus: A Meta-analysis. Clinics. 2020. 75, e1450. Epub April 17, 2020.https://dx.doi.org/10.6061/clinics/2020 /e1450

5. Yu, J., Zeng, T., Wu, Y., Tian, Y., Tan, L., Duan, X., Wu, Q., Li, H., \& Yu, L. Neutrophil-to-C3 ratio and neutrophil-tolymphocyte ratio were associated with disease activity in patients with systemic lupus erythematosus. Journal of clinical laboratory analysis. 2019. 33(1), e22633. https://doi.org/10.1002/jcla.22633

6. Rifa'i A, Kalim H, Kusworini, Wahono, CS. Effect of vitamin D supplementation on disease activity (SLEDAI) and fatigue in Systemic Lupus Erythematosus patients with hipovitamin D: An Open Clinical Trial. Indonesian Journal of Rheumatology .2016; Vol 8 No.2.

7. Hassanalilou, T., Khalili, L., Ghavamzadeh, S., Shokri, A., Payahoo, L., \& Bishak, Y. K. Role of vitamin D deficiency in systemic lupus erythematosus incidence and aggravation. Auto- immunity highlights. 2017; 9(1), 1. https://doi.org/10.1007/s13317-017-0101-x 
Ahmad Fauzi Lubis et.al. The relationship of neutrophil lymphocyte ratio and levels of vitamin D against disease activity systemic lupus erythematosus.

8. Oehadian, Amaylia \& Suryadinata, Hendarsyah \& Pramudyo, Riardi \& Alisjahbana, Bachti. The role of neutrophyl lymphocyte count ratio as an inflammatory marker in systemic lupus erythematosus. Acta medica Indonesiana.2013; 45. 170-4.

9. Mok C, Birmingham D, Ho L, Hebert L, Song H, Rovin B. Vitamin D deficiency as marker for disease activity and damage in systemic lupus erythematosus: a comparison with anti-dsDNA and anti-C1q. Lupus. 2012;21:36-42

10. Cardona-Cardona, A. F., \& Cerón y Cerón, J. A. Vitamin D in Colombian patients with systemic lupus erythematosus and its correlation with disease activity. Lupus. 2020.
1096120332093778. doi:10.1177/09612033 20937783

11. Guan SY, Cai HY, Wang P, et al. Association between circulating 25hydroxyvitamin $\mathrm{D}$ and systemic lupus erythematosus: a systematic review and meta-analysis. Int J Rheum Dis . 2019; 22: 1803-1813.

How to cite this article: Lubis AF, Zubir Z, Ginting AW. The relationship of neutrophil lymphocyte ratio and levels of vitamin $\mathrm{D}$ against disease activity systemic lupus erythematosus. International Journal of Research and Review. 2021; 8(10): 320-325. DOI: https://doi.org/10. 52403/ijrr.20211043 